\title{
METAFÍSICA DO IRRACIONAL - MAL RADICAL EM SCHELLING E SCHOPENHAUER
}

Jair Barboza *

RESUMO - Este artigo intenta mostrar as bases conceituais de uma metafísica do irracional em Schelling e Schopenhuaer, quando ambos os autores identificam na vontade a essência cega e irracional do mundo.

PALAVRAS-CHAVE - Schelling. Schopenhauer. Vontade. Mal radical.
ABSTRACT: This article aims to show the conceptual basis of a metaphysics of the irrational according to Schelling and Schopenhauer, when both autors identify in the will the blind and irrational essence of the world.

KEYWORDS - Schelling. Schopenhauer. Will. Radical evil.

\section{Colocação do problema}

A imagem moderna do homem é fortemente marcada pelo cogito de Descartes, ou seja, por uma "substância pensante", racional, que apreende a natureza do mundo sem nada deixar escapar a essa matriz pensante e, se o deixa, é para depois realocar esse resquício no pensamento, como um momento que lhe passara à margem, mas é agora processado cognitivamente. Se, de um lado, Kant segue o caminho cartesiano, quando, como teórico da Ilustração, confere à razão prática o poder de legislar na moral e na destinação histórica do homem, ao atribuir um foco imaginário com idéias à ação dos seres racionais e à ciência mesma, já entre os pós-kantianos surge, por outro lado, uma desconfiança em face dos poderes da razão. Esta é levada a tal limite de sua capacidade cognitiva, em vista de solucionar o enigma do mundo, que sobra algo que ela não pode realocar nela mesma como um momento de si. Aqui refiro-me a Schelling, ao sentenciar em seu Über das Wesen der menschlichen Freiheit: "Não há em suprema e última instância nenhum outro ser

* Professor de Filosofia na PUCPR.

\begin{tabular}{|l|l|l|l|l|l} 
VERITAS & Porto Alegre & v. 54 & n. 2 & maio/ago. 2009 & p. 187-196
\end{tabular}


senão o querer. O querer é ser-origiário (Ursein)". Com isso, há um marcante despotenciamento da razão que logo em seguida irá repercutir em Schopenhauer, ao consumar a revolução involuntária iniciada por Schelling e em definitivo apontar a razão como um mero momento do querer, ao dizer que o conhecimento, o intelecto, é "algo acidental e exterior", por consequência a obscuridade "não é uma mancha escura e casual em meio à região da luz, ao contrário, o conhecimento é uma luz em meio à obscuridade originária e sem limites, na qual o conhecimento se perde" (Schopenhauer, 1985, p. 273).

Nesse sentido, Schelling desencadeia e Schopenhauer consuma uma revolução no pensamento ocidental, a partir da qual se redesenha a imagem do homem, ao instaurar-se uma crítica contundente à razão, em verdade uma denúncia do narcisismo intelectual do ser humano, pois os impulsos e as volições passam a definir a sua natureza íntima e nuclear, que em verdade é uma natureza essencialmente irracional, algo depois caracterizado como o mal radical.

Dessa perspectiva, este estudo se concentra na noção de irracional volitivo como o mal radical, trabalhando com a obra principal de Schopenhauer, ou seja, O mundo como vontade e como representação, e a obra Freiheitsschrift ${ }^{1}$ de Schelling.

\section{Schelling}

Em Sobre a essência da liberdade humana e seus objetos correlatos, de 1809, Schelling retoma o eixo da sua filosofia primeira - a Naturphilosophie, filosofia-da-natureza -, em que afirma, depois da "intuição intelectual" do absoluto, em especial no escrito $\mathrm{Da}$ alma cósmica, que o absoluto, o incondicionado, manifesta-se no mundo mediante um "prazer infinito", tendo-se nessa manifestação o seu "afirmar-se-a-si-mesmo" como "querer o infinito", "em todas as formas, graus e potências da realidade" (Schelling, 1856-1861, II, p. 361-362). O mundo diante de nós ou "natureza naturada" é a cópia desse querer ou "natureza naturante". Com isso, o filósofo pretende dizer que uma natureza primeira mais natural se manifesta numa natureza segunda refletida em objetos. Contudo, na totalidade da natureza nada é exterior a ela mesma, de forma que o absoluto mesmo se encontra no menor grão de areia. Trata-se nessa "atividade" producente infinita não de um querer determinado pela razão prática, em sentido kantiano (herança das possibilidades reflexivas e intervenientes no mundo da substância pensante cartesiana), mas de um querer primário e insubordinado a categorias ou máximas, vale dizer,

1 Esse é o modo como os comentadores se referem abreviadamente ao escrito Über das Wesen der menschlichen Freiheit. 
um querer do qual se originam as próprias leis morais. Vale dizer, a razão prática apenas traduz com suas leis o querer originário. Todo imperativo racional de ação traduz as possibilidades de ato fincadas em uma matriz volitiva originária. A lei moral tem, em última instância, como fonte, um estado em nós "do qual não podemos ser conscientes a não ser pelo ato do querer mesmo..." (Schelling, 1856-1861, I, p. 432-433).

Nesse sentido, a razão não constrange a vontade, não tem poder sobre ela, mas é algo que lhe é subordinado, apenas reconhecendo o caráter da ação cuja fonte é o absoluto mesmo, pois a lei moral só é válida na medida em que é "sancionada pela vontade absoluta", e no absoluto não há lei moral, pois ele foge a qualquer tipo de delimitação, pura espontaneidade infinita que é. Não será surpresa, pois, quando, no mencionado escrito sobre a liberdade, o autor retomar a tese do querer originário e o definir nos seguintes termos.

"Não há em suprema e última instância nenhum outro ser senão o querer. O querer é ser-originário. Apenas a esse cabem todos os seus predicados, isto é, ausência-de-fundamento, eternidade, independência do tempo, autoafirmação. Toda a filosofia se esforça apenas em encontrar a sua suprema expressão." (Schelling, 1856-1861, II, p. 351).

Com isso, o trabalho de despotenciamento do racional, iniciado na filosofia-da-natureza, é retomado. Schelling dirá que Deus - nome agora escolhido por ele para designar o absoluto - possui um "fundamento" (Grund) de sua "existência" (Existenz); porém, esse "fundamento" é destituído de faculdade de entendimento. Um "fundamento sem-fundo" (Ungrund) ou, como o autor também o nomeia, um abismo em Deus, algo que nele "não é ele mesmo" (nicht Er Selbst ist), "o lado obscuro" (dunkel Seite) de sua alma, que é a "natureza" (Natur) nele ou o seu inconsciente. Se essa natureza sem fundo em Deus faz com que a divindade desconheça a si, no entanto, é dela que se origina o próprio Deus, é dela que ele dá a luz a si mesmo, pois exterior à unitotalidade absoluta não há nada, quer dizer, a existência de Deus provém de sua obscuridade ou seu princípio irracional, caos originário no centro mais central da divindade. Ao dar a luz a si, aquilo que é mais central em Deus possibilita depois a manifestação dele no mundo, pois o mundo é revelação de Deus. É a expansão do centro para a periferia. Com isso, as criaturas, revelações da divindade, carregam em si o duplo princípio divino, luz e sombra. Todo nascimento, luz, só o é a partir da escuridão: "a semente tem de ser atirada na terra e morrer na escuridão, para que a mais bela figura luminosa se eleve e se desenvolva na luz do sol". Do mesmo modo, prossegue Schelling, o homem é figurado no escuro do útero, porém, a partir dessa escuridão, desse destituído-de-entendimento, crescem depois os pensamentos luminosos. 
Assim, o autor, em um exercício titânico de metafísica que é o seu escrito sobre a liberdade, vai examinando a natureza mais íntima da alma divina, o fundamento de sua existência, a natureza nele, para lá encontrar o sem-regra, a base inapreensível de toda realidade, o caos primitivo. E as criaturas, por serem automanifestações de Deus, guardam necessariamente o caos primeiro de onde emanaram. Elas são luz e sombra, amor e ódio, bondade e maldade ao mesmo tempo. O resultado é que, a qualquer momento, podem deixar irromper na finitude, através de si, o sem-regra. A escuridão, a noite pode a qualquer momento devorar a luz do dia. Daí os estados de tristeza, a melancolia, a doença, enfim, um momento de irrupção do mal, pertencente à raiz metafísica mesma dos seres, isto é, pertencente a Deus mesmo, daí ser esse mal o mal radical. Noutros termos, são momentos em que se exprime nos rostos das criaturas o seu vínculo com a base caótica da existência, o lado obscuro de Deus. É, conclui Schelling, o "resto" que "não se deixa dissolver no entendimento", mas permanece para sempre "unidade infundada" (unergründliche Einheit), uma espécie, por assim dizer, de marca registrada do abismo da divindade no humano, do infinito no finito.

Só que, depois de assim corajosa e surpreendentemente despotenciar a razão, trabalhando de maneira provocativa com um Deus estranho a si, que se desconhece, que perdeu um de seus principais atributos conferidos pela tradição teológica, a onisciência, portanto, logo depois de ter atravessado a fronteira do racional para o irracional e nomear o querer infinito como sem fundamento e mal radical do mundo, Schelling, curiosamente, retorna, como que assustado por um perigo. No seu escrito sobre a liberdade, o que vemos na parte final é o drama de um filósofo que, de um lado, já não encontra mais na razão a justificativa para o princípio do mundo e, no entanto, tenta a todo custo agarrar-se à possibilidade de uma razão como matriz lógica e ordenadora das coisas, que a tudo apreende. Vemos nas páginas finais desse denso e intrigante escrito uma torção argumentativa que declina de assumir uma despedida do racional como princípio do mundo, já antes efetuado. Nesse horizonte, o objetivo secreto de Schelling passa a ser o de evitar a conclusão de que Deus é o responsável pelo mal, transferindo ao homem essa responsabilidade. A esse caberá o mal por herança, como nos estados de tristeza, melancolia e doença; contudo, é creditado ao homem o lugar por excelência da maldade, precisamente por conta de sua queda, isto é, por seu desprendimento da infinitude. A criatura humana guarda porém em si o duplo princípio divino, Grund e Existenz, "fundamento" e "existência", e, quando a sua vontade particular se rebela contra o querer infinito, explica Schelling, aí precisamente realiza-se o mal, como no caso da doença, em que uma parte do organismo tenta uma vida própria, porém falsa. A conclusão a tirar é que 
no homem se consuma a força do princípio obscuro de Deus, daquilo que nele não é ele mesmo. Desse modo, Deus realiza no homem a sua bondade e o seu amor infinitos, pois o mal humano lhe serve de contraste, do mesmo modo que a luz só se revela caso haja a escuridão, e o amor só se houver ódio; igualmente, o estado saudável do organismo só é bem percebido na doença de uma de suas partes, essa funcionando como reconhecimento da bondade de um organismo harmônico anterior à parte rebelada, que precisamente nessa rebelião torna o mal exclusivo para si. Decorre dessa "falsa vida" a intranquilidade, a inquietação, visto que se trata de mau uso daquilo que há de mais precioso, a liberdade. O mal, a doença, vistos a partir da finitude, é não saber se servir da liberdade: ficamos doentes por nossa exclusiva responsabilidade. Contudo, o próprio fato de sermos finitos, mas guardando o duplo princípio divino em nós, nos arrasta a um conflito entre finitude e infinitude, entre negativo e positivo, que potencializa todo o drama do ser (humano), o drama da própria queda (negatividade) a partir da infinitude (positividade), essa que no entanto ainda pulsa em cada um. O mal, portanto, é um momento em que a criatura não consegue manter o equilíbrio de sua natureza polar, dúplice, e ilusoriamente aposta que a finitude é a infinitude, que o negativo é o positivo. O homem encontra em si "o mais profundo abismo" e "o mais elevado céu". Ele é infinitude, mas, ao decair na finitude é responsável por essa queda, por essa tentativa de liberdade absoluta, e nessa tentativa é que a finitude vive a si mesma como finita e é nela mesma, por divorciar-se do todo, o negativo radical. Em outros termos, como dirá o autor em Filosofia e religião, "a finitude é em si mesma a condenação".

Ora, no intuito de salvar a bondade de Deus - e aqui está o cerne do argumento schellinguiano -, o filósofo observa que Deus mesmo, ao dar a luz a si, passa da potência de seu fundamento à sua existência "em ato" (actu). Contudo, retroativamente, o ato confere realidade à potência. Em outros termos, a existência já fundada de Deus possibilita o seu fundamento infundado.

"Deus tem em si um fundamento íntimo de sua existência, que nesse sentido lhe antecede enquanto existente. Mas, por seu turno, Deus é de novo o prius do fundamento, na medida em que o fundamento, enquanto tal, não poderia sê-lo, se Deus não existisse como actu" (Schelling, 1856-1861, II, p. 358).

Dizendo de outro modo: se seguirmos a imagem de um círculo, tão apreciada por Schelling, a periferia do círculo é que dá sentido ao centro. O círculo é aquela figura em que todos os pontos extremos estão equidistantes do centro. Ora, por ser inegável que essa definição pressupõe a referência do círculo ao seu centro, só a partir do qual se pode traçá-lo, é inegável, por consequência, que o círculo só existe depois de a periferia ter sido traçada, logo, só a partir dela é que o centro adquire, 
retroativamente, a sua realidade, embora paradoxalmente seja do centro que se irradia a periferia. Nesses termos, e é isso que quer dizer Schelling, se Deus racional in actu é a periferia, só se pode falar na realidade do seu centro irracional, isto é, de Deus em potência, de seu fundamento infundado, a partir da periferia mesma, isto é, a partir de Deus existente. Assim, o infundado, o obscuro, o irracional é absorvido no fundado, na luz, no racional. No círculo não há contradição, diz o autor, em que aquilo que gera o uno, o centro mais originário, invisível, é de novo gerado pelo uno, pela periferia. Quer dizer, o autor muda o registro e agora faz uma correção daquela passagem em que o querer era definido como ser originário e sem fundamento, irracional; doravante, o entendimento é, em verdade, concebido enquanto prius da vontade. A palavra final de Schelling será, então, que a vontade perfeita é aquela em que há entendimento, pois o entendimento é propriamente "a vontade na vontade". Portanto, o retorno ao racional foi efetuado! O filósofo, por torções contínuas dos argumentos, apesar de vislumbrar em um primeiro momento o irracional volitivo como o mais primário do mundo, ignora esse desvelamento e impede-se de identificar e solucionar uma aporia em seu pensamento.

Com isso, o drama de sua filosofia primeira se torna especialmente tenso em Freiheitsschrift: precisamente, ter notado o caos e o semregra como prius do mundo, sem contudo explorar todas as implicações filosóficas que essa descoberta, essa abertura de horizontes traria.

Essa aporia no pensamento de Schelling indica como a razão mostrava sinais de esgotamento nas hostes idealistas. O abismo do incondicionado, no qual a razão teme se perder, ao qual se referia Kant em sua primeira crítica, transforma-se em Schelling no drama da travessia das fronteiras do racional, para, logo em seguida, dar-se a tentativa desesperada de retorno. O filósofo, apesar de ter vislumbrado o querer como o centro originário e irracional do mundo, desiste de seguir adiante nesse caminho, retornando ao regaço e à proteção da razão. Ao meu ver, caberá a Schopenhauer consumar essa revolução de pensamento.

\section{Schopenhauer}

Schopenhauer conhecia em detalhes o escrito sobre a liberdade de Schelling, como mostram as marginálias de um exemplar dessa obra encontrado em sua biblioteca, preservada nos seus arquivos em Frankfurt. Schopenhauer nota a armadilha conceitual em que Schelling se envolve e a desarma.

Em Schopenhauer, a vontade como princípio do mundo é também definida, nos termos adiantados por Schelling, como "sem-fundamento" (grundlos) e exterior ao tempo. A ela cabem os mesmos predicados do ser originário enunciados no escrito sobre a liberdade. Ela é "um 
impelir abafado, obscuro, distante de qualquer capacidade imediata de conhecimento". É "um ímpeto cego" (blinder Drang), um esforço contínuo e destituído de alvo. A vontade é primária, é a natureza naturada da natureza naturante; no entanto, ao contrário de Schelling, em momento algum adquire a sua realidade via entendimento. $O$ entendimento não é a vontade na vontade, mas um mero instrumento para seres como os homens e os animais, destinado a ajudar na sua sobrevivência, mais dificultosa devido à complexidade de seus organismos. É só em vista dessa ajuda que o intelecto (entendimento mais razão) surge e, com ele, o mundo como representação com todas as suas formas. Diz Schopenhauer:

"Até então pura e simples Vontade, doravante é simultaneamente representação, objeto do sujeito que conhece. A Vontade, que até então seguia na obscuridade o seu impulso, com extrema certeza e infalibilidade, inflamou... uma luz para si, meio este que se tornou necessário para a supressão da crescente desvantagem que resultaria da profusão e da índole complicada de seus fenômenos, o que afetaria os mais complexos deles." (Schopenhauer, 1988, I, p. 212-213).

Dessa perspectiva, o intelecto não passa de uma lanterna do querer, e a razão é secundária, não só em referência à Vontade, mas também em referência ao entendimento, pois ela só pode formar conceitos após receber intuições. A razão reflete o mundo intuitivo, forma representações de representações; seus conceitos depuram as intuições feitas pelo entendimento; o seu edifício reflexivo está apoiado no mundo da experiência, que por sua vez manifesta o querer cósmico, que é o querer do próprio homem e do animal. Com isso, o querer permanece o irracional puro, completamente separado das representações conceituais ou intuitivas, pois essas são temporais, e a vontade é exterior ao tempo. Schopenhauer, assim, firma a sua posição em oposição a Schelling. O conhecimento, seja do entendimento, seja da razão, simplesmente serve ao querer, é "instrumental" (mekané) no auxílio necessário à sobrevivência de suas objetivações mais complexas, os homens e os animais.

Schopenhauer dirá, respondendo a Schelling e aos idealistas em geral, que o conhecimento, portanto, o intelecto, é "algo acidental e exterior, por consequência a obscuridade não é uma mancha escura casual em meio à região da luz, ao contrário, o conhecimento é uma luz em meio à obscuridade originária e sem limites, na qual o conhecimento se perde"2. A vontade é a coisa-em-si do mundo que se manifesta em graus crescentes de distinção e completude, sendo o homem o mais elevado deles. Tais graus são as ideias arquetípicas em sentido platônico, correspondentes às espécies da natureza, desde o reino inorgânico até a consciência

2 Citado na divisão anterior. 
humana. Porém, em si mesma a Vontade é "apenas um ímpeto cego e irresistível", que é de vida, pois o que ela sempre quer é a vida. "Vontade de vida" é uma expressão pleonástica, pois onde há vontade haverá vida. Só que nesse ponto Schopenhauer em realidade converge para soluções schellinguianas, já que o querer em Schelling é definido como uma "alma cósmica", "organismo universal". Contudo, Schelling, como vimos, recua do irracional como princípio do mundo, e o conhecimento, ao fim, é não só o que há de mais nobre no homem, mas o que define a natureza em si do absoluto, a vontade sem entendimento sendo uma vontade imperfeita, visto que, para o idealista oscilante entre um princípio racional e irracional do mundo, o "entendimento é propriamente a vontade na vontade" e só assim a vontade é perfeita. No autor de $\mathrm{O}$ mundo..., diferentemente, não se verifica semelhante oscilação conceitual. $O$ homem não conhece e depois quer o que conhece, como pretendem as filosofias idealistas, mas antes quer e só depois conhece (percebe) o que quis; consequentemente, só depois conhece a ação e o alvo aos quais levou o seu querer. O querer é absolutamente primário e inconsciente, o conhecimento é secundário, adicionado "como instrumento pertencente ao fenômeno da Vontade". Cada homem é o que é mediante a sua vontade. "Ele se conhece, portanto, em consequência e em conformidade à índole de sua vontade, em vez de, segundo a antiga visão, querer em consequência e em conformidade ao seu conhecer" (Schopenhauer, 1988, I, p. 384).

Mas, sem dúvida, Schopenhauer é estimulado por Schelling. Muitas vezes, inclusive, ele se preocupou tanto com a grande proximidade do seu conceito de Vontade àquele enunciado pela filosofia schellinguiana que se sentiu obrigado a vir a público fazer uma autodefesa para a posteridade, dizendo, nos Fragmentos sobre a história da filosofia, que o descobridor de uma verdade é tão-somente quem

"a conheceu desde os seus fundamentos e a meditou em suas consequências, desenvolvendo todo o seu conteúdo, abarcando a extensão de seu domínio, expondo-a assim com plena consciência de seu valor e validade, de maneira distinta e coerente" (Schopenhauer, 1988, IV, p. 135).

Do mesmo modo, prossegue, o descobridor de uma coisa não é aquele que a tomou casualmente uma vez nas mãos e depois a deixou escapar, mas sim quem reconheceu o seu valor e o destacou e conservou. Do mesmo modo, arremata, o descobridor da América não foi o primeiro náufrago que lá chegou carregado pelas ondas, mas Colombo.

Penso que a autodefesa de Schopenhauer é aceitável. Não que Schelling ignorasse a envergadura do seu conceito de vontade e o tenha tomado casualmente nas mãos; o seu escrito sobre a liberdade mostra o contrário. No entanto, o querer como ser-originário jamais foi por Schelling compreendido como princípio puramente irracional do mundo. Ao fim, como 
vimos, o entendimento é a vontade na vontade, que assim é vontade perfeita. Schelling, portanto, teve um vislumbre e, nesse sentido, não pode ser considerado o Colombo do querer como puro princípio irracional do mundo.

Mas, além da gênese dessa descoberta, o que também gostaria aqui de destacar é que o horizonte que Schelling abre e Schopenhauer amplia é propriamente um grande mérito desses pensadores. Foi a partir daí que as chamadas filosofias do impulso, como a de Nietzsche, puderam se mover, bem, sobretudo, a psicanálise de Freud. Com isso, creio serem pertinentes as seguintes palavras de Wittgenstein: "O mérito propriamente de um Copérnico ou de um Darwin não foi a descoberta de uma teoria verdadeira, mas sim de um novo e frutífero aspecto" (apud Zentner, 1995, p. x). E isso Schelling e Schopenhauer o fizeram. Schelling anunciando, Schopenhauer consumando a revolução que foi a descoberta do irracional para a filosofia.

Mas, é Schopenhauer quem assume todas as consequências do despotenciamento da razão e leva a cabo a descoberta do irracional, tornando-o em definitivo princípio do mundo e a razão um mero momento dele. Quando digo "com todas as consequências" é no sentido de que admitir um tal princípio do mundo acarreta ao mesmo tempo assumir um pessimismo metafísico, ou seja, o mal radical impera nos seres. Temse aí a "pecha" de inimigo da vida, com a qual o filósofo de Frankfurt é identificado pela maioria dos comentadores, não sem uma certa razão; porém, é preciso notar que, em momento algum, na primeira edição de sua obra principal, ele usa o termo "pessimismo", embora lá esteja a famosa frase "toda vida é sofrimento". Mas, o sofrimento, a tristeza das criaturas, já havia sido identificado como o símbolo do irracional no rosto dos seres, por Schelling. Dessa forma, ambos os filósofos são pessimistas em seu olhar clínico sobre a existência, a finitude, o negativo, a densa escuridão que se carrega e a qualquer momento pode tragar a luz. No entanto, Schelling vê a manifestação do mal na finitude como o contraste imprescindível para a infinita bondade de Deus, pois a luz só é luz devido à escuridão. A palavra final de Schelling é: "O amor é o que há de supremo. O amor é aquilo que existia antes que o fundamento e antes que o existente (como separados) existissem" - embora o filósofo caia em dúvida e conclua que esse amor não era ainda amor, mas: "como devemos descrevê-lo?". Já em Schopenhauer a palavra final é a obscuridade primária do cosmo. O seu pessimismo metafísico não admite conciliações, e por ele descortina um mundo de dor e tédio como pólos opostos do sofrimento, portanto, constituintes do nervo mesmo da finitude. A Vontade é uma autodiscórdia essencial e se vê essa autodiscórdia em toda parte, no seu espelho que é o mundo, em lutas incessantes, guerras de todos contra todos, com alternância da vitória, 
sim, mas nunca o fim da batalha, do pólemos que - como sentenciava Heráclito, antecipando Schopenhauer (e depois Nietzsche) - é o pai de todas as coisas. A razão não consegue erradicar esse mal radical; ao fim, pode inclusive, sem sabê-lo, arquitetar friamente um espaço de irrupção desse irracional (como, pense o leitor, os campos nazistas e stalinistas de concentração). A arquitetura da destruição vaza o poder destrutivo da Vontade autofágica, e a razão apenas trabalhou para isso, foi mais uma vez instrumento, sem conseguir claramente mensurar uma poder de destruição que se volta contra ela mesma.

\section{Conclusão}

Cabe sublinhar que o irracional cego e volitivo como princípio do mundo não deve significar de maneira alguma uma volúpia em face dele, pois o mesmo é a fonte, para Schelling, da tristeza das criaturas, da condenação inscrita na finitude mesma, do perigo do caos estabelecerse a qualquer momento e sem aviso na ordem corrente do mundo; e, para Schopenhauer, é a autodiscórdia da Vontade, da qual provém a luta de todos contra todos na natureza, onde quem não devora é devorado, porque o egoísmo de parte a parte desencadeia múltiplas formas de crueldade, guerras, etc.

Mas, se de um lado, para ambos os autores, o mal radical é a mais íntima, infinita, incondicionada natureza do mundo, de outro lado, uma descoberta filosófica dessa envergadura de maneira algum implica alegria em face do objeto descoberto. A positividade de tal objeto é pura violência. Caberia, assim, pensar uma cura em face dele. Schopenhauer chamará essa cura de negação da Vontade, acessível porém em seu grau máximo e duradouro apenas aos santos (o místico), em graus menores e passageiros, no entanto, àqueles que fruem esteticamente o belo. Já Schelling vislumbra, ao fim de um processo histórico de revelação do absoluto, "a redissolução da finitude no absoluto mesmo" (Wiederauflösung in die Absolutheit), anulando desse modo a sua separação do infinito. Com isso, o negativo (finito) se torna positividade (infinito), embora inconsciente.

\section{Referências}

SCHELLING. Sämmtliche Werke. 1856-1861. Edição de K. F. A. Schelling. Sttutgart: Cotta. "Von der Weltseele" (II); "Über das Wesen der menschlichen Freiheit" (II); "Abhandlungen zur Eläuterung des Idealismus der Wissenschaftslehre" (I).

SCHOPENHAUER. Werke. Edição "letzter Hand" de Ludger Lütkehaus. Zürich: Haffmans, 1988. "Die Welt als Wille und Vorstellung" (I); "Parerga und Paralipomena" (IV). . Metaphysik der Sitten. München: Piper, 1985.

ZENTNER, M. Die Flucht ins Vergessen. Darmstadt: WBG, 1995. 